\title{
Kayın ve kavak odunlarında bazı fiziksel özelliklerle yoğunluk ilişkisinin belirlenmesi
}

\author{
Bekir Cihad Bal $^{1 *}$, İbrahim Bektaş ${ }^{2}$
}

\section{$\ddot{\mathbf{O} z}$}

Masif ahşap malzeme geçmişten günümüze birçok farklı alanda kullanılmıştır. Özellikle, kolay temin edilebilmesi, ucuz olması, kolay işlenebilmesi, estetik bakımdan cazip olması gibi birçok üstün özelliklere sahiptir. Odunun özellikleri üzerine ağaç türü, rutubet miktarı, odun türü (genç odun-olgun odun veya öz odun-diri odun) ve odun kusurlarının etkili olduğu bilinmektedir. Bu çalışmada, odunun fiziksel özellikleri ile yoğunluğu arasındaki ilişki belirlenmeye çalışılmıştır. Bu amaç için, kayın (Fagus orientalis L.) ve kavak (Populus x euramericana I-214) odunları üzerinde denemeler yapılmıştır. Denemelerde, odunun tam kuru yoğunluğu, genişleme yüzdesi, lif doygunluk noktası ve rutubet miktarı belirlenmiştir. Denemelerde TS 2470, TS 2471, TS 4083 ve TS 4084 numaralı standartlar kullanılmıştır. Tam kuru yoğunluk ile diğer fiziksel özellikler arasındaki ilişki regresyon denklemleri ile belirlenmeye çalışılmıştır. Bu ilişkiler dağılım grafikleri ile gösterilmiştir. Elde edilen bulgulara göre; tam kuru yoğunluk miktarı arttıkça genişleme yüzdelerinin arttığı ve rutubet miktarının azaldığı belirlenmiştir.

Anahtar kelimeler: tam kuru yoğunluk, fiziksel özelikler, kayın odunu, kavak odunu

\section{Determination of relationship between density and some physical properties in beech and poplar wood}

\begin{abstract}
Solid wood material has used in many different areas from the past to the present day. In particular, it has many outstanding features such as being easy to procure, cheap, easy to process, attractive from aesthetic standpoint. It is known that wood species, moisture content, wood type (juvenile wood-mature wood or heart wood-sap wood) and wood imperfections are effective on wood properties. In this study, the relationship between physical properties and density of wood were determined. For this purpose, experiments carried out on beech (Fagus orientalis L.) and poplar (Populus x euramericana I-214) woods. In the experiments, the oven dry density of wood, swelling percentages, fiber saturation point and moisture content were determined. TS 2470, TS 2471, TS 4083 and TS 4084 standards were used in the experiments. The relationships between oven dry density and other physical properties were determined by regression equations. These relationships showed by distribution graphs. According to findings; it was determined that as the amount of oven dry density increased, the percentage of swelling increased and the percentage of moisture content decreased.
\end{abstract}

Keywords: Oven dried density, physical properties, beech wood, poplar wood 


\section{Giriş}

Ağaçlardan elde edilen odun hammaddesi, geçmişten günümüze, yeni bazı ürünlerin üretilebilmesi için önemli bir hammadde ve ayrıca en önemli mühendislik malzemelerinden birisi olmuştur. Günümüzde, odun hammaddesinden elde edilen yonga levha, lif levha, heraklit levha, kontrplak ve masif panel gibi kompozit yarı mamul malzemeler, mobilya ve dekorasyon işleri başta olmak üzere, değişik amaçlar için kullanılmaktadır. Odunun veya odundan elde edilen yonga veya kaplamaların bazı özelliklerinin iyileştirilmesiyle compreg, impreg, staybwood, accoya ve werzalit gibi bazı ürünler de geliştirilmiştir.

Ahşap malzemenin kendine has bazı önemli özellikleri bulunmaktadır. Diğer mühendislik malzemeleri ile kıyaslandığında, ahşap malzeme kullanım yerinde istenen ve istenmeyen bazı özelliklere sahiptir. Örneğin; ahşap malzeme ile plastik kıyaslandığında toprakla temas eden yerlerde çürüme özelliği bakımından plastik çok daha dayanıklıdır. Ancak, şekillendirme veya makinelerde işleme özelliği bakımından ahşap malzeme için basit makinelere ihtiyaç duyulur. Metaller mekanik performans bakımından elbette ahşaptan daha iyidir. Ancak işlenmesi ve şekil verilmesi zordur. Beton günümüzde en önemli inşaat malzemelerinden birisidir. Ancak bu malzemelere göre ahşap malzemenin estetik bakımdan üstün olması, kolay işlenip şekillendirilmesi, basit gereçlerle birleştirilmesi, maliyetinin düşük olması, doğa dostu olması, doğada bol bulunması, karbon tutucu olması ve yenilenebilen bir malzeme olması gibi üstün özellikleri bulunmaktadır.

Ahşap malzemenin yukarıda sayılan üstün özelliklerinin yanında üç temel yönde farklı özellikler göstermesi (anizotropi), yoğunluğuna bağlı olarak fiziksel, mekanik, kimyasal ve diğer teknolojik özelliklerinin değişiklik göstermesi, ağaçlardan alındığı yere göre bu özelliklerinin tamamının değişiklik göstermesi gibi istenmeyen özelikleri bulunmaktadır. Masif ahşap malzemede yoğunluk artıkça genel bir kural olarak mekanik özellikler artmaktadır. Eğilme direnci, elastikiyet modülü ve şok direnci ile yoğunluk arasında artandoğrusal bir ilişki vardır. Yapılan önceki çalışmalarda, birçok araştırmacı bu ilişkiyi belirlemiştir (Kollmann ve Cote, 1968; Bektaş ve ark., 2002; Bal ve ark., 2013).

Masif ahşap malzemenin fiziksel özellikleri genel olarak yoğunluk, odun-su ilişkileri, daralma ve genişleme özellikleri, lif doygunluk noktası, termik özellikleri, elektriksel özellikleri ve akustik özellikleri olarak siralanmaktadır (Kollmann ve Cote, 1968; Bozkurt ve Göker, 1996; Örs ve Keskin, 2001). Bu fiziksel özelliklerle yoğunluk arasında önemli bir ilişki olduğu yapılan önceki çalışmalarda belirlenmiştir. Örneğin; odun yoğunluğu arttıkça daralma ve genişleme yüzdelerinin arttığı (Kollmann ve Cote, 1968; Bektaş ve Güler, 2001; Pliura ve ark., 2005; Kord ve ark., 2010), termik, akustik ve elektriksel özelliklerinin değiştiği (Kollmann ve Cote, 1968) bildirilmiştir.

Ağaçlarda enine kesit incelendiğinde odun oluşumu bakımından, öz odun ve diri odun şeklinde iki farklı oluşumun meydana geldiği ve bunun yanında genç odun ve olgun odun olarak da iki farklı odun kısmının oluştuğu bilinmektedir. Çoğu ağaç türünde genç odun kısmı öz odun kısmının ortasında kalan ve ilk 5 ile 30 yıl sonucu oluşan yıllık halkaları kapsamaktadır. Yapılan önceki çalışmalarda genel olarak, test örnekleri bütün enine kesiti kapsayacak şekilde hazırlanmış ve bu öz odun-diri odun veya genç odun-olgun odun farklılıkları göz önüne alınmamıştır. Ancak, bu farklıkların yoğunluk ve dolayısıyla fiziksel özellikler üzerinde önemli farklılıklara sahip olabileceği düşünülmektedir. Bu noktadan hareketle bu çalışmada, Türkiye'de önemli bir kullanım alanına sahip olan ve aralarında yoğunluk bakımından büyük farklılıklar bulunan kayın ve kavak odunlarında öz odun ve diri odun kısımları ayrı gruplar halinde çalışılarak yoğunluk ile fiziksel özellikler arasındaki ilişkiler belirlenmeye çalışılmıştır. 


\section{Materyal ve Metot}

\subsection{Materyal}

$\mathrm{Bu}$ çalışmada, materyal olarak kayın (Fagus orientalis L.) ve kavak (Populus $\mathrm{x}$ euramericana I-214) odunları kullanılmıştır. Kayın tomrukları Karabük ili, Yenice ilçesinden ve kavak tomrukları Karabük ili, Eskipazar ilçesinde özel bir şahsa ait kavak sahasından alınmıştır. Kayın ve kavak tomruklarından test örneklerinin hazırlanacağı seksiyonlar alınmıştır. Daha sonra bu seksiyonlardan fiziksel özelliklerin belirlenmesi için laboratuar numuneleri kesilmiştir. Her deney için hazırlanan örneklerin boyutları ve nasıl elde edildikleri metot kısmında anlatılmıştır. Fiziksel özellikler ile ilgili olarak yapılan testlerde her iki ağaç türünde, öz odun-diri odun ayrımı yapılarak test grupları ayrı ayrı hazırlanmıştır.

\subsection{Metot}

Yuvarlak odundan laboratuar numunesi için kereste kesimi Şekil 1'de gösterildiği gibi TS 2470'e göre yapılmıştır. Her deney için aynı tomruktan eşit sayıda test numunesi alınmıştır. Test örnekleri alınırken, öz odun ve diri odundan alınan test örnekleri sayısı eşit tutulmuştur. Her grup için 150 adet ve toplamda 600 adet test örneği hazırlanmıştır. Tüm fiziksel özellikler bu test örnekleri üzerinde yapılmıştır. Bu standarda göre deney parçalarının hazırlanması, deneyin yapılışı, hesaplama ve sonuçların gösterilmesi sırasıyla şu şekildedir; deney parçalarının biçim ve boyutları odunun denenmesine ilişkin standartlarda belirtildiği gibi hazırlanmıştır. Lif doğrultusu uzunluk eksenine paralel ve deney parçası başlarında yıllık halkalar iki yüze paralel ve diğer iki yüze dik olarak ayarlanmıştır.

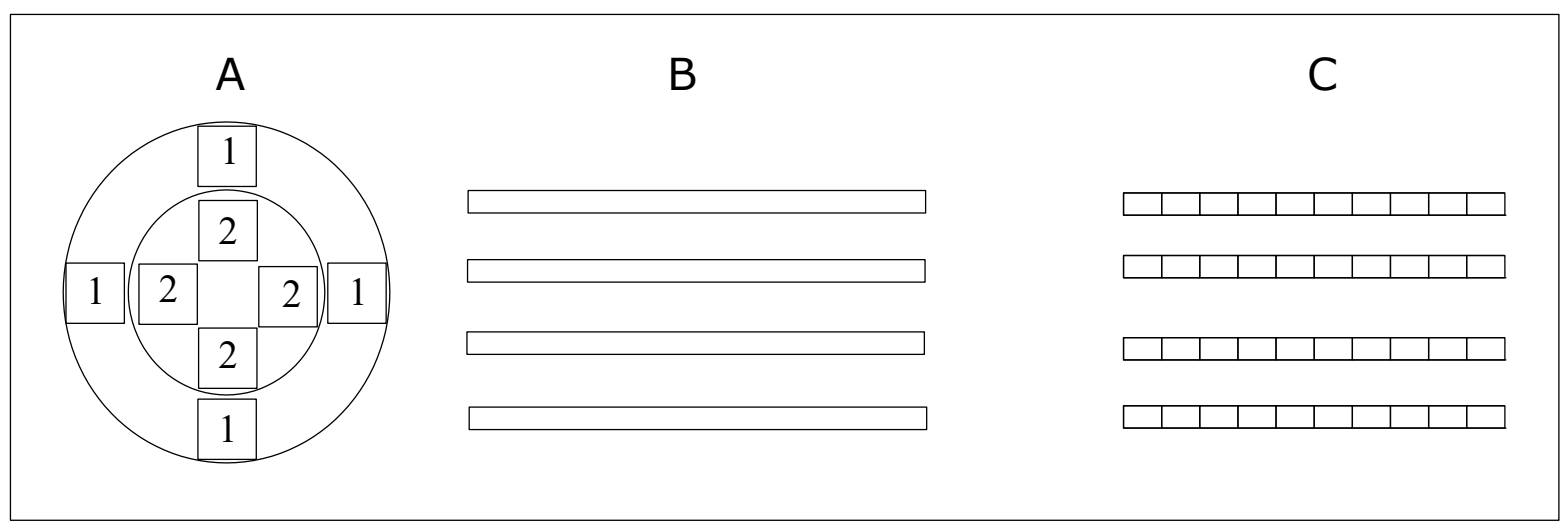

Şekil 1. Tomruk enine kesitinden öz odun (2'ler) ve diri odundan (1'ler) kadronların alınması (A), kadronlardan elde edilen çıtalar (B), çıtalardan elde edilen test örnekleri (C)

\subsubsection{Tam kuru yoğunluk miktarının belirlenmesi}

Tam kuru yoğunluk ölçümleri TS 2472'ye göre yapılmıştır. Buna göre örnekler kurutma dolabına konmuş ve sıcaklığı kademeli olarak $103 \pm 2{ }^{\circ} \mathrm{C}$ 'ye çıkarılarak, yüksek 1sıda zarar görmesi önlenmiştir. Kurutma dolabında örnek ağırlıklarının sabit hale gelmesini müteakip, dolaptan çıkarılan örnekler desikatöre alınarak, soğumaları sağlanmış daha sonrada ağırlıkları ve üç yöndeki boyutları ölçülerek formül (1)'e göre hesaplanmıştır.

$$
\mathrm{D}_{0}=\mathrm{M}_{0} / \mathrm{V}_{0} \quad\left(\mathrm{~kg} / \mathrm{m}^{3}\right)
$$

Burada; $\mathrm{D}_{0}$, Tam kuru yoğunluk $\left(\mathrm{kg} / \mathrm{m}^{3}\right), \mathrm{M}_{0}$, Tam kuru ağırlık $(\mathrm{kg}), \mathrm{V}_{0}$, Tam kuru hacimdir $\left(\mathrm{m}^{3}\right)$. 


\subsubsection{Daralma miktarının belirlenmesi}

Daralma miktarlarının belirlenmesinde TS 4083 'te verilen esaslara uyulmuştur. $\mathrm{Bu}$ standartlarda adı geçen çekme teriminin yerine daralma, şişme teriminin yerine ise genişleme terimleri kullanılmıştır. Bu standarda göre; deney parçaları tabanı 20 x $20 \mathrm{~mm}$ ve lif doğrultusundaki uzunluğu $30 \mathrm{~mm}$ olan prizma biçiminde hazırlanmıştır. Deney parçalarının ağırlığı değişmez hale gelinceye kadar bir kap içerisinde $20 \pm 5^{\circ} \mathrm{C}$ sıcaklıkta damıtık su içerisine batırılmış sonra ölçümler yapılmış ve kaydedilmiştir. Deney parçaları normal oda şartlarında yaklaşık \%12-15 rutubete kadar kurutulmuştur. Daha sonra deney parçaları kurutma dolabında $103 \pm 2{ }^{\circ} \mathrm{C}$ sicaklıkta değişmez ağırlığa ulaşıncaya kadar kurutulmuştur. Tam kuru haldeki ölçüleri alınmıştır. Daralma miktarlarının hesaplanmasında aşağıdaki formüllerden (2 ve 3) yararlanılmıştır;

$$
\beta=\frac{\mathrm{L}_{\text {max }}-\mathrm{L}_{\text {min }}}{\mathrm{L}_{\text {max }}} \times 100
$$

$\mathrm{Bu}$ formülle teğet, radyal ve boyuna yöndeki ölçüler kullanılarak, teğet yöndeki daralma yüzdesi $\left(\beta_{t}\right)$, radyal yöndeki daralma yüzdesi $\left(\beta_{r}\right)$ ve boyuna yöndeki daralma $\left(\beta_{1}\right)$ tespit edilmiştir. Hacmen daralma yüzdesi $\left(\beta_{\mathrm{V}}\right)$ ise aşağıdaki formül (3) ile hesaplanmıştır.

$$
\beta_{\mathrm{V}}=\beta_{\mathrm{r}}+\beta_{\mathrm{t}}+\beta_{1}(\%)
$$

Burada; $\mathrm{L}_{\max }$, lif doygunluk noktası üzerinde rutubet derecesine sahip deney parçasının sırasıyla radyal, teğet ve boyuna doğrultularda mm olarak boyutları, $\mathrm{L}_{\mathrm{min}}$ ise deney parçasının kurutulduktan sonra sirasıyla radyal, teğet ve boyuna doğrultularda mm olarak boyutlarıdır.

\subsubsection{Genişleme miktarının belirlenmesi}

Genişleme miktarının belirlenmesi için TS 4084 numaralı standart kullanılmıştır. Bu standartlara göre deney parçaları; tabanı 20 x $20 \mathrm{~mm}$ ve lif doğrultusundaki uzunluğu $30 \mathrm{~mm}$ olan prizma biçiminde hazırlanmıştır. Deney parçaları boyut ve biçimlerini bozabilecek çatlaklar oluşmayacak biçimde kurutma dolabında $103 \pm 2^{\circ} \mathrm{C}$ 'de sıcaklıkta değişmez boyutlara ulaşıncaya kadar kurutulmuştur. Daha sonra deney parçalarının boyutları değişmez hale gelinceye kadar bir kap içerisinde $20 \pm 5^{\circ} \mathrm{C}$ sıcaklıkta damıtık su içerisine batırılmıştır. Daha sonra tam yaş haldeki son ölçüleri alınmıştır. Genişleme miktarlarının hesaplanmasında aşağıdaki formüllerden (4 ve 5) yararlanılmıştır.

$$
\alpha=\frac{\mathrm{L}_{\text {max }}-\mathrm{L}_{\text {min }}}{\mathrm{L}_{\text {min }}} \times 100
$$

$\mathrm{Bu}$ formülle teğet, radyal ve boyuna yöndeki ölçüler kullanılarak, teğet yöndeki genişleme yüzdesi $\left(\alpha_{t}\right)$, radyal yöndeki genişleme yüzdesi $\left(\alpha_{r}\right)$ ve boyuna yöndeki genişleme $\left(\alpha_{1}\right)$ tespit edilmiştir. Hacmen genişleme yüzdesi $\left(\alpha_{V}\right)$ ise aşağıdaki formül (5) ile hesaplanmıştır.

$$
\alpha_{\mathrm{V}}=\alpha_{\mathrm{r}}+\alpha_{\mathrm{t}}+\alpha_{1}
$$

Burada, $\mathrm{L}_{\max }$, lif doygunluk noktası üzerinde rutubet derecesine sahip deney parçasının sırasıyla radyal, teğet ve boyuna doğrultularda $\mathrm{mm}$ olarak boyutları ve $\mathrm{L}_{\min }$ ise deney parçasının kurutulduktan sonra sırasıyla radyal, teğet ve boyuna doğrultularda $\mathrm{mm}$ olarak boyutlarıdır. 


\subsubsection{Rutubet miktarının belirlenmesi}

Rutubet miktarının belirlenmesi için TS 2471 numaralı standartta belirtilen formül kullanılmıştır. Rutubet yüzdesi, genişleme miktarının belirlenmesi testi sonunda, test örneklerinin rutubetleri ölçülerek hesaplanmıştır.

$$
\mathrm{R}_{\max }=\left(\left(\mathrm{M}_{\mathrm{r}}-\mathrm{M}_{0}\right) / \mathrm{M}_{0}\right) \times 100
$$

Burada, $\mathrm{M}_{\mathrm{r}}$, deney parçasının suda bekletme sonunda ulaşılan maksimum rutubetteki ağırlı̆̆ 1 (gr), $\mathrm{M}_{0}$, deney parçasının tam kuru ağırlı̆̆ (gr). Her bir deney parçası için elde edilen sonuçların aritmetik ortalaması hesaplanmış ve bu değer deney parçalarının ortalama rutubet miktarı olarak gösterilmiştir.

\subsubsection{Lif doygunluk noktasının belirlenmesi}

Lif doygunluk noktası rutubeti (LDN), hücre çeperinin tamamen su ile doygun olduğu fakat hücre lümenlerinde suyun hiç bulunmadığı durumdur. Lif doygunluğu rutubet derecesi aşağıdaki formül (7) kullanılarak hesaplanmıştır.

$$
\mathrm{LDN}=\alpha_{\mathrm{V}} / \mathrm{D}_{0}(\%)
$$

Burada, LDN, Lif doygunluk noktasını $(\%), \alpha_{V}$, hacmen genişleme yüzdesini $(\%), \mathrm{D}_{0}$, ise tam kuru yoğunluk değerini göstermektedir $\left(\mathrm{g} / \mathrm{cm}^{3}\right)$.

\section{Bulgular ve Tartışma}

Çalışma sonunda elde edilen fiziksel özelliklere ait bulgular Çizelge 1'de verilmiştir. Çizelgede verilen bulgular incelendiğinde, tam kuru yoğunluk değerinin kavak odununda kayın odunundan daha düşük olduğu görülmektedir. Kavak öz odunun yoğunluğu diri odununkinden daha düşük olduğu, ancak, kayın öz odununun yoğunluğunun kayın diri odununkinden daha yüksek olduğu görülmektedir. Yoğunluk değerlerinin bu şekilde farklı olmasının önemli sebepleri ağaç türünün farklı olması, kavak odunun hızlı gelişen bir tür olması ve ayrıca öz odun içerisinde genç odun oluşumunun bulunmasıdır. Bunun yanında kayın öz odununun yoğunluğunun diri odundan daha yüksek çıkmasının önemli bir nedeni öz odundan iletim kanallarının tül ile tıkalı olması geçirgenliğini engelleyen bazı ekstraktiflerin birikmiş olması sayılabilir.

Çizelgede verilen daralma ve genişlemeye ait değerler incelendiğinde kayın odununun tüm daralma genişleme değerlerinin kavak odununun değerlerinden daha yüksek olduğu görülmektedir. Yoğunluğun daralma ve genişleme üzerine etkisi önceki çalışmalar dikkate alındığında bu sonuç beklenen bir sonuçtur. Kavak öz odununun hacmen daralma değeri $\% 10.5$ ve diri odununun ise \%10.3 olduğu görülmektedir. Ancak fark istatistiksel olarak önemli değildir $(\mathrm{P}>0.05)$. Elde edilen bu bulgular yoğunluk değerleri de göz önünde bulundurularak yorumlandiğında, bir farklılığın olduğu görülmektedir. Beklenen sonuç, yoğunluğun yüksek olması sebebiyle kavak diri odununun daralma ve genişleme değerlerinin daha yüksek olmasıdır. Bunun önemli sebebinin kavak öz odununda yıllık halkaların oldukça geniş olması, genç odun oluşumu sebebiyle mikrofibril açılarının öz odunda farklı olması sayılabilir (Bozkurt ve Göker, 1996; Kord ve ark., 2010). Ayrıca, öz odun ile diri odun arasında lignin miktarının farklı olması da daralma ve genişlemeyi etkileyen faktörlerden olduğu bildirilmiştir (Bozkurt ve Erdin, 1997).

Daralma genişlemeyle ilgili olarak belirtilmesi gereken bir diğer konu; çizelgede verilen tüm teğet yöndeki daralma ve genişleme değerleri radyal yöndekilerden daha büyük ölçülmüş olmasıdır. Bunun nedeni ise yıllık halkalarda yoğunluğu yüksek olan yaz odunu kısmının 
teğet yönde uzanması ve öz ışınlarının radyal yönde uzanması olduğu bildirilmiştir (Bozkurt ve Erdin, 1997). Ayrica, hücre çeperlerinde bulunan ligninin, hücre çeperinin radyal yüzeylerinde daha fazla bulunduğu ve bunun daralma ve genişlemeyi azaltıcı etki yaptığ belirtilmiştir (Bozkurt ve Erdin, 1997; Simpson ve Tenwolde 1999).

Çizelge 1'de verilen lif doygunluk noktası ile ilgili bulgular incelendiğinde, en küçük lif doygunluk noktasının kayın diri odununda (\%28.6) ve en büyük lif doygunluk noktasının ise kavak öz odununda (\%35.4) elde edildiği görülmektedir. Lif doygunluk noktası kavak ve kayın öz odununda diri odundan daha yüksek bulunmuştur. Lif doygunluk noktası hacmen genişleme miktarının tam kuru yoğunluk değerine bölünmesiyle hesaplanmıştır. Bunun haricinde, Babiak ve Kúdela (1995) tarafından belirtildiği gibi sekiz farklı metotla lif doygunluk noktası hesaplanabilmektedir. Farklı yöntemlerle ölçülen lif doygunluk noktası ölçümleri farklı sonuçlar vermektedir. Yapılan bu çalışmada elde edilen lif doygunluk noktası sonuçları hacmen daralma ve tam kuru yoğunluk değeri faktörleri ile hesaplanmıştır ve bu faktörlerin etkisindedir. Bu nedenle yoğunluğu düşük olan kavak öz odununda en yüksek lif doygunluk noktası ölçülmüştür.

Denemeler sonunda elde edilen rutubet içeriği Çizelge 1'de verilmiştir. Elde edilen bulgular incelendiğinde rutubet miktarının odun yoğunluğu arttıkça azaldığı görülmektedir. Kavak öz ve diri odununun rutubet yüzdeleri kayın öz ve diri odununkinden daha yüksektir. En yüksek değer kavak öz odununda \%167 olarak ölçülmüştür. En küçük değer ise kayın öz odununda \%81 olarak ölçülmüştür.

Çizelge 1. Fiziksel özelliklere ait bulgular

\begin{tabular}{|c|c|c|c|c|c|c|c|c|c|c|c|}
\hline & $\mathbf{D}_{\mathbf{0}}$ & $\boldsymbol{\beta}_{\mathrm{t}}$ & $\boldsymbol{\beta}_{\mathbf{r}}$ & $\beta_{1}$ & $\boldsymbol{\beta}_{\mathbf{v}}$ & $\boldsymbol{\alpha}_{\mathrm{t}}$ & $\boldsymbol{\alpha}_{\mathbf{r}}$ & $\boldsymbol{\alpha}_{1}$ & $\boldsymbol{\alpha}_{\mathbf{v}}$ & LDN & $\mathbf{R}$ \\
\hline & $\mathrm{kg} / \mathrm{m}^{3}$ & $(\%)$ & $(\%)$ & $(\%)$ & $(\%)$ & $(\%)$ & $(\%)$ & $(\%)$ & $(\%)$ & $(\%)$ & $(\%)$ \\
\hline \multicolumn{12}{|c|}{ KAVAK DİRİ ODUNU } \\
\hline $\mathrm{x}$ & 376 & 7.3 & 3.0 & $\ldots$ & 10.3 & 7.9 & 3.1 & $\ldots$ & 10.9 & 29.2 & 156 \\
\hline SS & 33 & 0.5 & 0.3 & $\ldots$ & 0.6 & 0.6 & 0.3 & $\ldots$ & 0.7 & 2.0 & 15 \\
\hline $\mathrm{v}$ & 9 & 7.0 & 10.3 & $\ldots$ & 6.2 & 7.6 & 10.6 & $\ldots$ & 6.6 & 6.9 & 10 \\
\hline \multicolumn{12}{|c|}{ KAVAK ÖZ ODUNU } \\
\hline $\mathrm{x}$ & 317 & 7.3 & 3.2 & $\ldots$ & 10.5 & 7.9 & 3.3 & $\ldots$ & 11.2 & 35.4 & 167 \\
\hline ss & 30 & 0.6 & 0.5 & $\ldots$ & 0.9 & 0.7 & 0.6 & $\ldots$ & 1.0 & 2.21 & 24 \\
\hline $\mathrm{v}$ & 9 & 8.5 & 16.6 & $\ldots$ & 8.3 & 9.2 & 17.3 & $\ldots$ & 8.8 & 6.2 & 15 \\
\hline \multicolumn{12}{|c|}{ KAYIN DİRİ ODUNU } \\
\hline $\mathrm{x}$ & 616 & 11.0 & 4.7 & 0.3 & 16.0 & 12.4 & 5.0 & 0.2 & 17.6 & 28.6 & 89 \\
\hline ss & 46 & 1.2 & 0.7 & 0.2 & 1.7 & 1.5 & 0.8 & 0.2 & 2.0 & 2.2 & 16 \\
\hline $\mathrm{v}$ & 7 & 10.5 & 14.6 & 79.8 & 10.4 & 11.7 & 15.3 & 68.4 & 11.1 & 7.9 & 18 \\
\hline \multicolumn{12}{|c|}{ KAYIN ÖZ ODUNU } \\
\hline $\mathrm{x}$ & 626 & 11.3 & 4.9 & 0.2 & 16.4 & 12.8 & 5.2 & 0.2 & 18.1 & 28,9 & 81 \\
\hline ss & 49 & 1.2 & 0.7 & 0.2 & 1.6 & 1.5 & 0.8 & 0.1 & 2.0 & 1.82 & 13 \\
\hline $\mathrm{v}$ & 8 & 10.6 & 14.4 & 76.5 & 9.8 & 12.0 & 15.2 & 60.1 & 10.9 & 6.3 & 16 \\
\hline
\end{tabular}

$\mathrm{D}_{\mathrm{o}}$ : tam kuru yoğunluk değeri, $\beta_{\mathrm{t}}$ : teğet daralma yüzdesi, $\beta_{\mathrm{r}}$ : radyal daralma yüzdesi, $\beta_{1}$ : boyuna yönde daralma yüzdesi, $\beta_{\mathrm{v}}$ : hacmen daralma yüzdesi, $\alpha_{\mathrm{t}}$ : teğet genişleme yüzdesi; $\alpha_{\mathrm{r}}$ : radyal genişleme yüzdesi, $\alpha_{1}$ : boyuna genişleme yüzdesi, $\alpha_{v}$ : hacmen genişleme yüzdesi, LDN: lif doygunluk noktası, R: rutubet yüzdesi, x: aritmetik ortalama, ss: standart sapma, v: varyasyon katsayıs1 
Kavak ve kayın öz ve diri odunlarında yoğunluk ile hacmen genişleme arasındaki ilişkiyi gösteren dağılım grafiği Şekil 2, 3, 4 ve 5'de gösterilmiştir. Grafikler, grafik içinde verilen regresyon denklemleri ve belirtme katsayısı $\left(\mathrm{R}^{2}\right)$ incelendiğinde, her dört odun türü içinde ilişkinin doğrusal-artan bir ilişki olduğu ve belirtme katsayısına göre bu ilişkilerin güçlü olduğu görülmektedir. Odun yoğunluğu arttıkça genişleme yüzdesi artmaktadır. En güçlü ilişki belirtme katsayısı 0.69 olarak hesaplanan kayın diri odununda elde edilmiştir. $\mathrm{Bu}$ konuda yapılan önceki çalışmalarda da odun yoğunluğu arttıkça genişleme yüzdesinin arttığına dair sonuçlar elde edilmiştir (Mantanis ve ark., 1994; Simpson ve Tenwolde 1999; Pliura ve ark., 2005; Hernandez, 2007; Kord ve ark. 2010; Kiaei 2011). Öz odunda biriken ekstraktif maddeler (Mantanis ve ark., 1994) ve genç odun-olgun odun oluşumu, odun ile fiziksel özellikler arasındaki ilişkileri (Metsä ve ark., 2006; Bal ve Bektaş, 2012)ve ayrıca odun ile mekanik özellikler arasındaki ilişkileri de etkilemektedir. Odun yoğunluğu arttıkça mekanik özelliklerinde artmakta olduğu bildirilmiştir (Kantay ve ark., 2000; Güller ve Ay, 2001; Bao ve ark., 2001; Bektaş ve ark., 2002; Korkut ve Guller, 2008; Bal ve Bektaş, 2013; Bal, ve ark., 2012).

Lif doygunluk noktası ile tam kuru yoğunluk arasındaki ilişki Şekil 2, 3, 4 ve 5'de verilmiştir. Şekillerde verilen grafikler incelendiğinde, kavak öz ve diri odununda lif doygunluk noktası ile tam kuru yoğunluk arasındaki ilişkinin doğrusal azalan bir ilişki olduğu, ilişkinin kavak diri odununda daha güçlü $\left(\mathrm{R}^{2}: 0.44\right)$ olduğu görülmektedir. Ancak kayın öz ve diri odununda bir ilişki tespit edilememiştir. Kavak öz ve diri odununda elde edilen lif doygunluk noktası değerleri kayında elde edilenden daha yüksektir. Önceki bazı çalışmalarda, kavak odununun lif doygunluk noktası yüksek olan odun türlerinden olduğu belirtilmiştir (Kollmann ve Cote, 1968; Bozkurt ve Erdin, 1997). Kayın odununun lif doygunluk noktası genişleme yüzdesi ve tam kuru yoğunluğuna göre Bektaş ve Güler, (2001) tarafından \%28.5 olarak verilmiştir. Malkoçoğlu (1994) tarafindan ise \%30.13 olarak hesaplanmıştır. Bu çalışma ile önceki çalışmalardan elde edilen değerler benzerdir. Ancak, önceki çalışmalarda, lif doygunluk noktası ile tam kuru yoğunluk arasındaki ilişkiyi gösteren bir çalışmaya ulaşılamamıştır. Sunulan bu çalışmada, lif doygunluk noktası, genişleme yüzdesinin tam kuru yoğunluğa bölünmesi ile hesaplanmıştır. Elde edilen lif doygunluk noktası yüzdesi bu iki faktöre bağlıdır. Kayın odununun hacmen genişleme yüzdesi kavak odununkinden yüksektir. Ancak, yoğunluğu da yüksektir. Bu nedenle lif doygunluk noktası daha düşüktür. Ayrıca, hacmen genişleme yüzdesini etkileyen önemli faktörlerin; odundaki lignin miktarının fazlalığı, hücre çeperinde mikrofibrillerin kristalin kısımlarının fazlalı̆̆ı, öz 1şınlarının fazlalığı olduğu belirtilmiştir (Bozkurt ve Erdin, 1997). Bu durumda, odunun lif doygunluk noktası üzerine, genişleme yüzdesi ve yoğunluğu yanında, lignin miktarı, mikrofibrillerdeki kristalin kısımlar ve odunun anatomik özellikleri de etkilidir denebilir.

İki haftalık suya daldırma süresi sonunda elde edilen rutubet ile tam kuru yoğunluk arasındaki ilişki Şekil 2, 3, 4 ve 5'de verilmiştir. Dört grafikte de yoğunluk arttıkça rutubet miktarının azaldığı görülmektedir. Grafiklerdeki eğilim çizgileri, regresyon denklemleri ve belirtme katsayıları incelendiğinde rutubet ile tam kuru yoğunluk arasında doğrusal azalan bir ilişki olduğu görülmektedir. Çizelge 1'de verilen rutubet yüzdeleri incelendiğinde kavak odununun kayın odunundan daha yüksek rutubet yüzdesine sahip olduğu görülmektedir. Bunun önemli nedeni, hücre çeperine bağlanan bağlı su miktarı hariç, kavak odunun yoğunluğunun düşük olması ve birim hacimde serbest suyun yerleşebileceği daha fazla boşluk bulunmasıdır. Ancak, kayın odununda yoğunluğun yüksek olması nedeniyle boşluk miktarı daha azdır. Bu nedenle de kayın odununun rutubet yüzdesi daha düşük olmaktadır. Yapılan önceki çalışmalarda benzer sonuçlar elde edilmiştir (Bal ve Bektaş, 2012; Bal ve ark., 2012). 

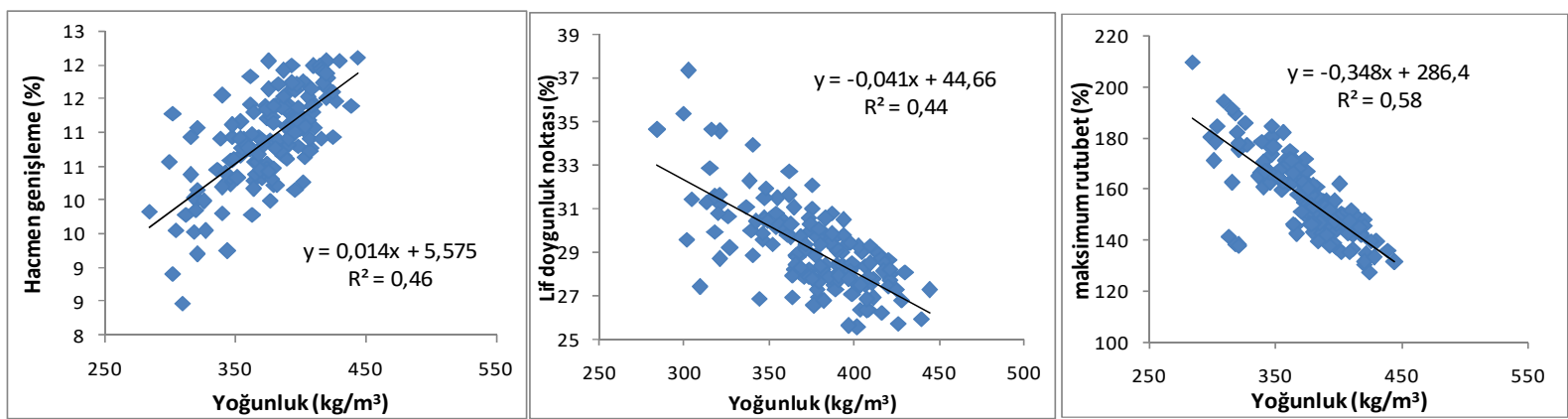

Şekil 2. Kavak diri odununda hacmen genişleme, lif doygunluk noktası ve rutubet ile yoğunluk ilişkisi
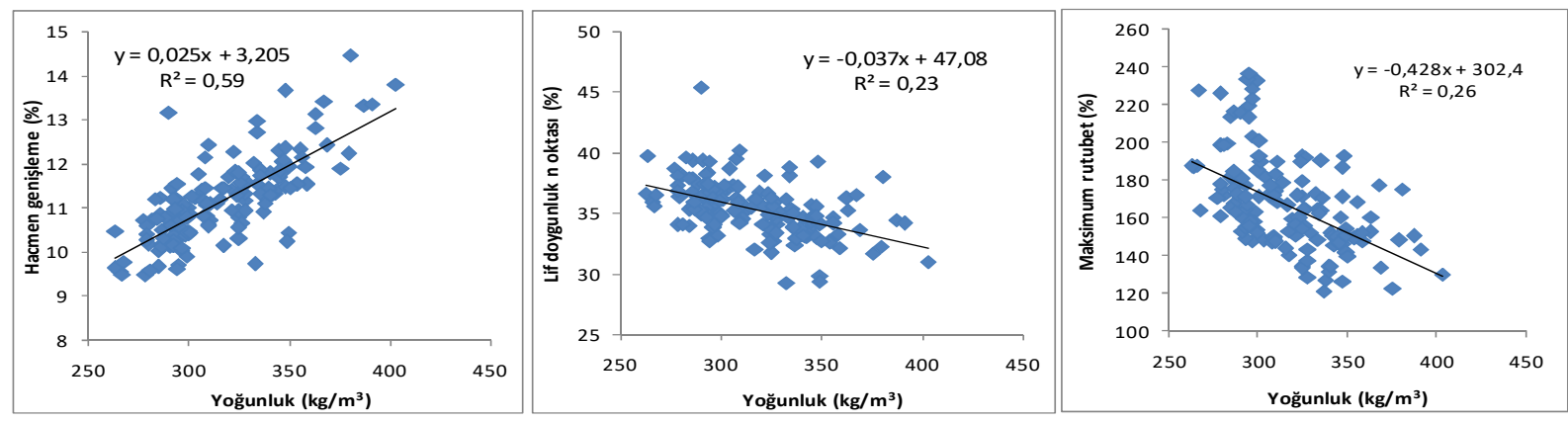

Şekil 3. Kavak öz odununda hacmen genişleme, lif doygunluk noktası ve rutubet ile yoğunluk ilişkisi
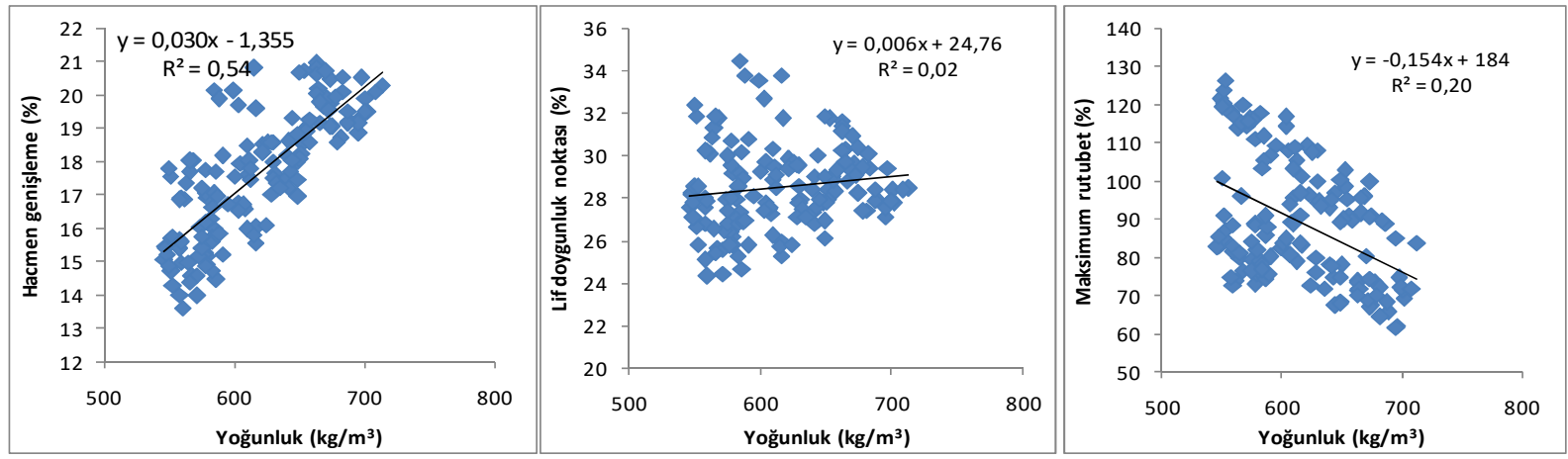

Şekil 4. Kayın diri odununda hacmen genişleme, lif doygunluk noktası ve rutubet ile yoğunluk ilişkisi
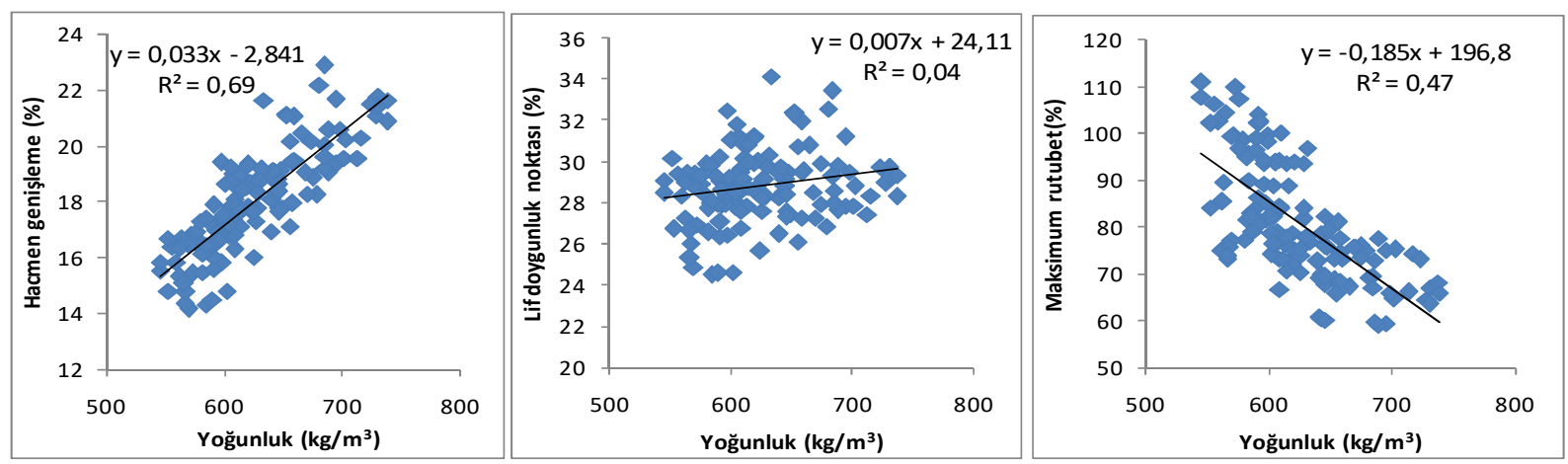

Şekil 5. Kayın öz odununda hacmen genişleme, lif doygunluk noktası ve rutubet ile yoğunluk ilişkisi 


\section{Sonuçlar}

Çalışma sonunda elde edilen verilere göre şu sonuçlara ulaşılmıştır;

- Kavak ve kayın öz ve diri odunlarında yoğunluk ile genişleme yüzdeleri arasında doğrusal-artan bir ilişki olduğu ve bu ilişkinin belirtme katsayısına göre güçlü bir ilişki olduğu belirlenmiştir.

- Yoğunluk ile lif doygunluk noktası arasında kavak öz ve diri odununda doğrusal-azalan bir ilişki olduğu belirlenmiştir. Ancak, kayın odununda ilişki belirlenememiştir. Bu farklılığın sebeplerinin, bu çalışmada lif doygunluk noktasının, genişleme yüzdesinin tam kuru yoğunluğa bölünmesi ile hesaplanmış olması ve ayrıca, odunun kimyasal içeriği, öz 1şınları, mikrofibrillerde bulunan kristalin kısımlar, odunun genişleme yüzdesi olduğu söylenebilir.

- Yoğunluk ile rutubet yüzdesi arasında doğrusal-azalan bir ilişki belirlenmiştir. Bunun, odun yoğunluğu arttıkça, serbest suyun yerleşebileceği odunda bulunan boşluk miktarının azalmasından kaynaklandığı söylenebilir.

\section{Teşekkür}

$\mathrm{Bu}$ çalışma, Kahramanmaraş Sütçü İmam Üniversitesi, Bilimsel Araştırma Projeleri Yönetim Birimi Başkanlığı tarafından 2009/3-2D numaralı proje kapsamında desteklenmiştir. $\mathrm{Bu}$ destekten dolayı KSÜ BAP birimine teşekkür ediyoruz.

\section{Kaynaklar}

Babiak, M., and Kúdela, J. (1995), A contribution to the definition of the fiber saturation point. Wood Science and Technology, 29(3), 217-226.

Bal, B. C., and Bektaş, I. (2012), The physical properties of heartwood and sapwood of Eucalyptus Grandis. Proligno, 8(4), 35-43.

Bal, B. C., and Bektaş, İ. (2013), The Mechanical Properties of Heartwood and Sapwood of Flooded gum (Eucalyptus grandis ) Grown in Karabucak, Turkey. Düzce Üniveristesi, Ormancıllk Dergisi, 9(1), 71-76.

Bal, B. C., Bektaş, İ.,ve Kaymakçi, A. (2012), Toros Sedirinde Genç Odun ve Olgun Odunun Bazı Fiziksel ve Mekanik Özellikleri. KSÜ Mühendsilik Bilimleri Dergisi, 15(2), 17-27.

Bal, B. C., Özdemir, F., ve Altuntaş, E. (2013), Masif ağaç malzeme ve tabakalı kaplama kerestenin vida tutma direnci üzerine karşılaştırmalı bir çalışma. Düzce Üniveristesi, Ormancılık Dergisi, 9(2), 14-22.

Bao, F. C., Jiang, Z. H., Jiang, X. M., Lu, X. X., Luo, X. Q., and Zhang, S. Y. (2001), Differences in wood properties between juvenile wood and mature wood in 10 species grown in China. Wood Science and Technology, 35(4), 363-375.

Bektaş, İ., ve Güler, C. (2001), Andırın Yöresi Doğu Kayını (Fagus orientalis L.) Odununun Bazı Fiziksel Özelliklerinin Belirlenmesi, Turk J Agric For, 25(4), 209-215.

Bektaş, İ., Güler, C., and Baştürk, M. A. (2002), Principal Mechanical Properties of Eastern Beech Wood (Fagus orientalis L.) Naturally Grown in Andirın Northeastern Mediterranean Region of Turkey, Turk J Agric For, 26(2002), 147-154.

Bozkurt, Y., ve Erdin, N. (1997), Ağaç Teknolojisi, İstanbul Üniversitesi, Orman Fakültesi Yayinlarl, No 445, İstanbul,1997. 
Bozkurt, Y., ve Göker, Y. (1996), Fiziksel ve Mekanik Ağaç Teknolojisi, Yılmaz Bozkurt, Yener Göker İ̈, Orman Fakültesi Yayınlarl, No:3944, İstanbul.

Güller, B., ve Ay, N. (2001), Artvin Yöresi sakallı kızılağaç (Alnus glutinosa subsp. barbata (C.A. Mey.) Yalt.) odununun bazı mekanik özellikleri, Turk J Agric For, 25, 129-138.

Hernandez, R. E. (2007), Moisture sorption properties of hardwoods as affected by their extraneous substances, wood density, and interlocked grain. Wood and Fiber Science, 39(1), 146-158.

Kantay, R., As, N., ve Ünsal, Ö. (2000), Ceviz (Juglans regia L .) Odununun Yoğunluğu ve Bazı Mekanik özellikleri, Turk J Agric For, 24(2000), 751-756.

Kiaei M., (2011), Anatomical, physical, and mechanical properties of eldar pine (Pinus eldarica) grown in the Kelardasht region, Turk J Agric For. 35 (2011), 31-42.

Kord B., Kialashaki A., and Kord B. (2010), The within-tree variation in wood density and shrinkage, and their relationship in Populus euramericana, Turk J Agric For, 34 (2010), 1-6. 2010.

Kollmann, F., and Cote, W. A. (1968), Principles of wood science and technology. Springer Verlag.

Korkut, S., and Guller, B. (2008), Physical and mechanical properties of European Hophornbeam (Ostrya carpinifolia Scop.) wood, Bioresource Technology, 99(11), 4780-4785.

Malkoçoğlu, A. (1994), Doğu kayını (Fagus Orientalis L.) odununun teknolojik özellikleri, Karadeniz Teknik Üniversitesi, Fen Bilimleri Enstitüsü, Doktora Tezi, Trabzon.

Mantanis, G. I., Young, R. A., and Rowell, R. M. (1994), Swelling of wood. Wood Science and Technology, 28, 119-134.

Metsä-Kortelainen, S., Antikainen, T., and Viitaniemi, P. (2006), The water absorption of sapwood and heartwood of Scots pine and Norway spruce heat-treated at $170^{\circ} \mathrm{C}, 190^{\circ} \mathrm{C}$, $210^{\circ} \mathrm{C}$ and $230^{\circ} \mathrm{C}$. Holz Als Roh - Und Werkstoff, 64(3), 192-197.

Örs, Y., ve Keskin, H. (2001), Ağaç malzeme bilgisi, Gazi üniversitesi ders kitabı, S:77, Ankara.

Pliura, A., Yu, Q., Zhang, S. Y., and Mackay, J. (2005), Variation in wood density and shrinkage and their relationship to growth of selected young poplar hybrid crooes. Agricultural and Environmental Database, 51(5), 472.

Simpson W., and Tenwolde A., (1999), Physical properties and moisture relations of wood, wood handbook, Wood as Engineering Material. FPL, GTR, 113, P:3-6, Madison. 1999.

TS 2470, Odunda fiziksel ve mekaniksel deneyler için numune alma metotları ve genel özellikler, TSE, Ankara.

TS 2471, Odunda fiziksel ve mekaniksel deneyler için rutubet miktarı tayini, TSE, Ankara.

TS 2472, Odunda fiziksel ve mekaniksel deneyler için birim hacim ağırlığı tayini, TSE, Ankara.

TS 4083, Odunda radyal ve teğet doğrultuda çekmenin tayini, TSE, Ankara.

TS 4084, Odunda radyal ve teğet doğrultuda şişmenin tayini, TSE, Ankara. 